\title{
Economics and Euthanasia
}

published in Health Services Management Research, 2001, vol. 14, pp. 62-3

\author{
Stephen Heasell \\ Nottingham Trent University \\ Burton Street \\ Nottingham \\ NG1 4BU \\ and \\ David Paton \\ Nottingham University Business School \\ Jubilee Campus \\ Wollaton Road \\ Nottingham \\ NG8 1BB \\ Email: David.Paton@nottingham.ac.uk \\ Tel: 00441158466601 \\ Fax: 00441158466667
}

\begin{abstract}
This paper argues that a cost-benefit type economic analysis of whether or not to prohibit euthanasia should not be undertaken by health services managers unless ethical issues have been resolved to a particular conclusion. A conclusion on ethical grounds in favour of the prohibition of euthanasia renders the consideration of economic criteria redundant. The case of the German euthanasia programme in the 1930s is used to illustrate the danger of attempting to combine ethical and economic criteria into a single decision rule.
\end{abstract}




\section{A Note on Economics and Euthanasia}

Abstract: This paper argues that a cost-benefit type economic analysis of whether or not to prohibit euthanasia should not be undertaken by health services managers unless ethical issues have been resolved to a particular conclusion. A conclusion on ethical grounds in favour of the prohibition of euthanasia renders the consideration of economic criteria redundant. The case of the German euthanasia programme in the 1930s is used to illustrate the danger of attempting to combine ethical and economic criteria into a single decision rule.

In recent years, considerable attention has been paid to the possibility of legalising euthanasia. Although the debate has been based largely around the ethical issues, any change in public policy on this issue could have important implications for the management of health services. It has been argued in this Journal (Ward, 1997) that, as a consequence, the ethical debate about euthanasia should not be divorced from an economic consideration of the costs and benefits to society of euthanasia. In this note we argue that, on the contrary, an economic analysis of euthanasia should be undertaken only if the ethical issues have been resolved in a particular way. In other words, an economic assessment of the case for or against euthanasia is not complementary to the ethical assessment but instead is dependent on its resolution.

Ward (1997) argues that ethics is concerned with individuals and "therefore does not take into account the societal perspective" (p. 33). He contrasts this with economics which is said to be concerned with the relative costs and benefits to society and can "help to determine if euthanasia is of benefit to the majority in society." (p. 33) Implicit in his argument is that the net benefit to the individual (from ethical considerations) can be compared with the net benefit to society (from economics) and that both can be included in an overall decision rule for whether or not to legalise euthanasia. This comparison would presumably have to be 
made using a common scale on which to measure all the benefits and costs.

The argument that ethical consequences or implications of euthanasia for an individual can be evaluated is based partly on the question of whether or not a value can be put on life. Ward (1997) draws on the health economics literature (e.g. Mooney, 1977) to suggest that a positive answer to this question is implicit in many health rationing decisions and is applicable to the euthanasia decision. An event which results in a death, however, involves not just a transition from a state of being alive to one of being dead; it is also set within a specific context. In particular, euthanasia (as defined by, for example, Leenan, 1984) also involves the specific act of a medical professional killing a patient. The ethical status of this act has implications both for individuals and for society. Thus, to be able to make an economic assessment of euthanasia, we would have to be able to evaluate the costs and benefits of this act of killing. That in turn would involve nothing less than a definition and a resolution of the ethical issues in a particular way.

We can consider two possible conclusions to the ethical debate. The first might be that the act of killing by euthanasia is ethically acceptable in some circumstances. In this case, it would be appropriate to consider the net benefits of the act to the individual patient along with the wider economic considerations. Alternatively, the conclusion might be that the act of killing by euthanasia is ethically unacceptable. In that case, it becomes impossible to draw up a scale on which to compare the net benefits of the act with the wider economic considerations. For example, the killing of an innocent person against their will might be considered ethically unacceptable under any circumstances. If so, it would be entirely inappropriate to move on to an economic evaluation of the overall net benefits to society of a policy to legalise the killing of that individual.

Ward (1997) asserts that "introducing an economic perspective is not incompatible 
with ethical issues" (p.40), whereas we argue that the decision to include an economic perspective to resolve the policy issue is conditional on a particular prior resolution of the ethical issues. Ward suggests that, from a reading of the literature, the ethics and the economics of euthanasia point in the same direction for policy; that is, against a complete prohibition (op. cit., p. 40). If that were indeed so (and the literature is not conclusive), then the decision implied by combining economic and ethical considerations would be the same as that implied by resolving the ethical issue first. Thus, the two different decision rules lead to the same decision in this case. This would not necessarily be the case, however, in all circumstances; that is, where the ethical considerations point towards one decision and the economics towards a different one. By proposing to compare ethics and economics of euthanasia whatever the circumstances, Ward implies that the decision rule is defined by a particular prior resolution of the ethical issues: one that finds an unqualified prohibition unacceptable.

A case study from this century may help to illustrate the argument. The euthanasia programme of Germany which commenced in the 1930's is well-documented (see, for example, Cleaver and Grant, 1998). Attempts to justify this programme concentrated on its economic benefits, for example that " 300,000 hospital beds would be made available by getting rid of mental patients" (Wertham, 1998, p.24). The use of economic arguments in this way was viewed by many as being inappropriate. This view was coupled with a judgement that the German euthanasia programme was ethically unacceptable. Once this conclusion on the ethical debate had been drawn, the discussion of the economic arguments which took place in Germany became at best irrelevant and at worst offensive.

In conclusion, we would urge economists and health managers to be careful before drawing on a conventional cost-benefit type of economic analysis to support ethically 
questionable policy proposals. Rather we should acknowledge that, in some cases, ethical considerations render the consideration of economic criteria redundant.

\section{References}

Cleaver, C, Grant, E and Rothe, M (1998), `Lessons From History's Most Calamitous Experience: events leading to the holocaust', in Wilkie, J.C. (Editor), Assisted Suicide and Euthanasia Past and Present, Cincinnati: Hayes, 5-15.

Leenan, H.J. (1984), 'The Definition of Euthanasia', Medicine and Law, 3, 333-8.

Mooney, G. (1977), The Valuation of Human Life, London: Macmillan Press.

Ward, P.R. (1997), 'Health Care Rationing: can we afford to ignore euthanasia?', Health Services Management Research, 10, 32-41.

Wertham, F. (1998), 'The Geranium in the Window', in Wilkie, J.C. (Editor), Assisted Suicide and Euthanasia Past and Present, Cincinnati: Hayes 
Lisa Deakin

Editorial Office

Publications Department

Royal Society of Medicine

1 Wimpole Street

London W1G 0AE

$27^{\text {th }}$ November 2000

Dear Ms Deakin,

Please find enclosed the proofs for the article 'Economics and Euthanasia' which is due to be published in Health Services Management Research.

I would be grateful if you would also note the change to my affiliation and to the address to which off-prints should be sent.

With best wishes,

David Paton (Dr)

Tel: (0115) 8466601

Fax: (0115) 8466667

Email: David.Paton@nottingham.ac.uk 
